\title{
7. Research, knowledge creation and technology transfer
}

\subsection{IMPORTANCE OF SCIENCE AND TECHNOLOGY FOR INNOVATION}

Conducting scientific research and generating new science-based knowledge is one of the main missions of research universities. Disseminating and transferring research-based outcomes are key to translating RII potential into RII delivery. Joint research and development (R\&D) programmes, science parks and other facilities have gained more and more importance in bringing together university researchers, local industry and other business practitioners. These RII pathways act as interfaces and catalysts: not only do they initiate and ease communication and cooperation, thus creating trust among partners, but they also enable and speed up the flow of ideas and knowledge, exchanges of staff, joint R\&D agenda setting and sharing of equipment. There are numerous RII pathways, also for 'embodied' interactions and 'tacit' knowledge flows, where connections and partnerships range from personal ties and small consulting assignments to large, longer-term research projects.

Universities are often crucial organisations in regional innovation systems, especially in those systems with an underdeveloped R\&D-led business sector or a lack of knowledge-intensive firms (Vallance et al., 2018). The knowledge generated by universities, and the transmission of the knowledge generated to local private sector actors or other (public sector) users, tends to have positive effects on a firm's innovation performance (e.g. Leten et al., 2014) and can be an important input to local or regional innovation systems. Many European research universities are heavily engaged in R\&D partnerships with business enterprises - either locally, within the wider region, or abroad. More and more of these engagements occur within the context of 'open innovation' environments, where departments and units at firms interact with a range of universities and other external sources to explore and develop innovative ideas and opportunities, and exploit these opportunities through multiple channels for commercialisation. Universities themselves may also adopt 'open' approaches on how they engage with local or (inter)national partners; see for instance the cases of Aalto University and Aalborg University mentioned in sections 5.2 
and 7.3. A university's integration in (inter)national R\&D networks can be beneficial to local cooperation and knowledge transfer within their regional innovation system: it may often be the knowledge generated elsewhere that is of particular relevance to a partner firm within a university's home territory.

Many of Europe's largest research-active universities are closely associated with a 'science park', a ‘technology park' or an 'innovation hub' (or equivalent entities under various other names). In most cases the science parks have been established by the university, often in collaboration with important research partners (such as university hospitals) and economic development partners or regional government agencies. Most of these parks or hubs have been designed with the specific intention of providing physical infrastructure for interactions between academia and industry, an environment in which academic researchers and R\&D staff working in the private sector can meet and exchange with one another, which also helps to stimulate new ideas and facilitate opportunities for collaborative research. In most cases these infrastructures include 'business incubation centres' or 'business accelerator centres' designed to support innovative new spin-outs emerging from the university, start-up firms, or attract other firms from outside the local region. The creation and survival of these revenue-generating university spin-offs is probably one of the most important RIIs in terms of economic impact (job creation, revenues and profits, network and cluster effects).

Knowledge and technology transfer to firms has been institutionalised within universities through the establishment of Technology Transfer Offices (TTOs), or other types of organisational entities aimed at engagement with the business sector. These dedicated units liaise between the university and industry at different levels and can incorporate a range of functions; facilitating the commercialisation of research findings, providing advice and handling legal issues related to intellectual property, but also registering or selling university-owned patents, licensing out university-developed patented technologies to existing firms, assistance on protecting university patents, arranging joint university-industry conferences or other forums to managing joint research projects and business ventures, creation of information portals for business partners, and support of university spin-off enterprises. Large TTOs within large research-intensive universities have a range of specific full-time employment positions of experts in technology transfer, intellectual property management, and business development. Increasingly TTOs are also expected to promote, shape and implement a university's technology, innovation and commercialisation strategy; especially at those 'entrepreneurial' universities that are very active in creating new 'spin-off' business enterprises with various forms of participation of university representatives and investments.

Sections 7.2 and 7.3 further describe how R\&D activities, science parks and other support facilities like TTOs help to develop and activate the RII potential 
of universities in the area of research, knowledge creation and technology transfer. These sections relate to 'RII resources' and 'RII delivery space' domains in our RII model. The final concluding section summarises the main findings and draws some general conclusions.

\subsection{RII RESOURCES: UNIVERSITY-BUSINESS CONNECTIONS AND INTERACTIONS}

Driven by the dynamics of the corporate world, the size and shape of regional innovation systems are ever-changing. Knock-on effects on related university infrastructures and facilities are inevitable. However, amidst these changing environments, structural features of those systems tend to be more robust and stable. For example, some university-industry partners have been established many decades ago, especially if they are dominated by large R\&D-active partner firms. Aalto University, for example, has a tradition of long-term research cooperation and co-creation with major companies in the region such as $\mathrm{ABB}$ and $\mathrm{SAAB}$. It signed a ten-year strategic cooperation arrangement with $\mathrm{SAAB}$ in 2017 , and with a total value of approximately $€ 20$ million. Other universities, such as the Catholic University of Leuven have built extensive regional networks, across many cities and closely connected to efforts to promote the region as a knowledge hub for foreign companies. Many of this university's collaboration platforms focus on its research strengths: materials science, medical technology, food and nutrition, and drug discovery in line with regional strengths (see Appendix B for more information on the RII profile of this university). The University of Aveiro is also an example of a university that organises its collaboration platforms and partner networks on a thematic basis. In this case, agro-food, multidisciplinary high-pressure, sea, moulds and plastics, bicycle and soft mobility, connected communities, forest and habitat.

Clearly, each university will define its own unique profile of universitybusiness partnerships. In its efforts to continuously strengthen the relationship with the region's business communities, Aalborg University has developed an interactive collaboration-promoting environment, including an online platform structure for 'open Innovation licensing', where firms can increase and mature their engagement with the university over time. This facilitates a cooperative learning process and also offers a way for the many non-innovative firms in the region to start engaging in research and innovation relationships with the university. These cooperation arrangements between regional businesses and the university range from innovation workshops involving students, student projects, and internships to cooperation in clusters and networks and, especially for strong and innovative companies, more contractually binding cooperation such as industrial PhDs, technology transfer, and research projects. 
Further information about this 'Aalborg model' can be found in Appendix C, the university's case study report.

Other universities organise some of their collaboration with industry through dedicated research centres. For example, the University of Bologna hosts seven industrial interdepartmental centres (CIRIs), where applied research is carried out in collaboration with local companies. These centres are part of the regional High Technology Network and are aimed at increasing knowledge transfer towards the regional industry. CIRIs are located in the five towns throughout the region where the University of Bologna has local branches. The Technical University of Turin invested $€ 30$ million to create 11 centres that perform research on 'breakthrough technologies' while sharing this infrastructure with large companies as well as small and medium-sized enterprises (SMEs). Additional programmes targeted at SMEs provide scientific tutoring and coaching services to help them develop and produce various kinds of innovative products and processes. Appendix D provides more information about the RII-relevant portfolio of facilities, activities at Technical University of Turin.

Business associations can be important intermediary organisations. Rovira i Virgili University has gradually developed a network, known as the Campus of International Excellence Southern Catalonia (CEICS), which connects business associations to its public research centres, technology centres and university hospitals. CEICS is seen as part of the broader region's Research Innovation Strategy for the Smart Specialisation of Catalonia (RIS3CAT). Further details about this CEICS and this university are presented in Appendix F.

Universities with a strong presence in the engineering sciences, or a business school on campus, tend to have a higher relative number of contacts with the business sector than universities with a relatively stronger specialisation in the social sciences, or arts and humanities. Consultancy and contract research have been a traditional channel of knowledge transfer for universities including Trieste. Services for regional firms constitute a very significant share of these contracts $(43.5 \%)$, providing a measure of engagement with regional industry. More than half of the contracts of the University of Trieste involve its engineering department. As a counter example, the University of Warsaw is remarkable for its large share of contract research in humanities and social science, partially a consequence of a US\$1 million grant by Google in 2013 to establish the interdisciplinary Digital Economy Laboratory (DELab). This facility has become the main hub for research into digital technologies, and their impact on economy and society within Central and Eastern Europe. Further information on the University of Warsaw's array of RII-relevant facilities and activities can be found in Appendix E. 


\subsection{RII DELIVERY SPACE: TECHNOLOGY TRANSFER OFFICES, PATENTS, AND OPEN INNOVATION}

The RII case studies show that many research-active universities, as well as comprehensive universities, run active and dynamic TTOs. Leuven Research \& Development (LRD) is a prominent example of a successful TTO in Europe; it was established in 1972 by the Catholic University of Leuven, which makes it one of Europe's oldest TTOs. LRD in Leuven is one of the biggest TTOs in Europe which supports all forms of exploitation of research results. Set up as an autonomous business unit within the university it now consists of a multidisciplinary team of over 100 experts. The TTO manages research collaboration agreements between the university and industry, the commercialisation of intellectual property, the creation of new ventures (spin-offs) and the development of science parks. The total revenue of all LRD supported activities increased to about $€ 210$ million in 2018 , part of which is used by academics to hire staff to sustain their research commercialisation ('valorisation') activities. LRD also takes an active role in influencing the development of innovation policy in Flanders, as well as in Europe. In Flanders, the regional legislation stipulates that in case of exploitation of an invention the inventors are entitled to a fair share of the proceeds. This allows the university to use a flexible and effective mechanism to provide incentives to staff - special divisions of the TTO have been set up, which are maintained independently from the central administration and act as virtual companies within the university. More information on LRD can be found in Appendix B, the RII self-appraisal report by the Catholic University of Leuven.

Over the last 20-30 years, most of the other research-active universities in Europe have also set up TTOs. For example, the University of Warsaw has now been involved in direct and indirect technology transfer processes for some twenty years. The university's Technology Transfer Centre (UOTT) provides professional services for intellectual property protection and offers support for the UW academics with patent issuing, licence granting or sale of rights. It also provides contacts and programmes for government or private funders and professional advice on academic IP protection (see Appendix F). Some of the more regionally oriented universities were later at setting up TTO type structures in their organisations; the University of Ruse and the University of Trieste in Italy established their TTOs as recently as 2008.

As universities learn from more and less successful experiences worldwide, their TTO business models and organisational structures continuously evolve and adapt. For example, the University of Bologna has been transforming its TTOs to cater for different demands related to knowledge transfer activities. 
The transformation of Bologna's IPR office into a Knowledge Transfer Office also meant an expansion of the services it offered. In doing so it works together closely with AlmaCube, the business incubator of the University of Bologna. The University of Bologna is considered a reference point at national and regional level, thanks to its contribution to the development and enhancement of the university community norms and practices in terms of intellectual property rights (IPR) and knowledge transfer. It was one of the first Italian research-active universities issuing an IPR regulation in 1996. As the example of Bologna shows, it is not only the technical universities which have set up formal structures to promote knowledge transfer. Other, comprehensive research-active universities such as Aalborg University, Eötvös Loránd University and Leiden University have also set up such organisational structures.

Attaining better results in utilising their intellectual property is a major issue at several universities. Since 2006, Aalborg University has insourced the entire commercialisation process and has constrained its patenting activities to the most viable and (potentially) most profitable inventions. This strategic change is one of the main reasons why it has become the biggest seller of inventions and discoveries among the universities in Denmark - 36\% of all commercialisations of research outputs in the period 2012-2016 belong to this university. Aalborg University has also established an innovation department ('AAU Innovation'), which, on the one hand, deals with the legal issues related to knowledge transfer, and on the other hand, facilitates the interaction of the university with research and education networks, local governmental authorities and local business organisations. The Open Innovation Licensing system of Aalborg University ensures risk-free technology licensing by providing a two-step process: the clients first obtain a trial licence to assess whether the invention matches their needs before signing the commercial licence (see Appendix C).

The universities of technology, several or which could also be labelled as 'entrepreneurial', have pushed their TTOs into new areas. Modern means of intellectual property management, and adopting 'open innovation' approaches, now enhance the process of commercialisation and transfer. The transformation of the Technical University of Turin's TTO into the new Technology Transfer and Industrial Liaison department constituted a reinforcement of its legal, administrative and methodological support to technology transfer activities. In 2016, the Technical University of Turin, supported by Banca Intesa and the Ministry of Economic Development, set up a project aimed at creating a unique entry point for patents filed from most of the Italian research-active universities and research centres. The objective is to provide greater opportunities for SMEs to access the pool of patents and related technologies (see Appendix D). 
The Technical University of Catalunya's Technology Transfer Centre, which was set up in 1987, was complemented eleven years later by an Innovation Office to provide a fuller range of services related to the commercial exploitation of research and technology development. Also in the Catalunya region, Rovira i Virgili University produced its first spin-off company in 1998. Since then 24 more companies have been set up, of which 15 are still active. These start-up and spin-off companies directly employ around 100 people and have generated a turnover of almost $€ 15$ million over the last ten years (see Appendix F).

Universities that are active in technology transfer tend to measure their success in technology transfer activities with quantitative indicators such as the number of patent filings or revenues earned on licences. The patent portfolios of the research-active universities under study are generally reported to have evolved quantitatively (in terms of volume) as well as qualitatively (with regards to selectivity and portfolio building). As an example of the latter, the Technical University of Catalunya currently has an extensive portfolio of patent families with more than 60 'market-oriented' patents of commercial value. With more than 600 registered patents the Technical University of Turin is a leading university in Italy. About $50 \%$ of its patents are co-owned with local companies or research centres. This university has a growing number of patent (co-)applications and licences to external firms but also its university spin-offs. These activities have generated around $€ 1$ million income from different sources and around $€ 0.7$ million on patent options (see Appendix D).

Aalto University is less focused on such quantitative indicators and performance statistics for RII analytics or assessment purposes. It argues that such indicators may not be measuring real impact and may in some cases even be counter-productive. Aalto University's Principles for Commercialisation of Intellectual Property (2017) define the primary goal of maximising societal impact through optimal utilisation of the research results. When new inventions are made, the respective university services support the recognition and protection of the intellectual property, as well as the transfer of rights to third parties, including newly formed start-ups. In case of inventions transferred on the basis of commissioned research agreements, the partner company has ownership or access rights to the results. Aalto University understands its role in its innovation ecosystem to be different and argues that this should be reflected in assessments. It considers that "in an integrated co-creation model the focus should be on the achievements of the ecosystem as a whole", and claims that "by not focussing on maximising its own technology transfer indicator values Aalto University facilitates the success of the other ecosystem members" (Aalto University RII self-appraisal report). In the same vein Aalto University has integrated the assessment of third mission activities into its excellence evaluations both at individual researcher and university level. 


\subsection{CONCLUSION}

The examples in this chapter aptly illustrate the variety of RII resources and delivery spaces among European research universities. Each university has its own RII profile of strengths and strategies. Nevertheless, several common enabling factors emerge that may significantly contribute to achieving successful RII. Extensive levels of industry-oriented regional engagement and involvement in regional R\&D networks is one of those factors. Human capital is important: staff and students engaged in research collaboration and resource exchanges between universities and innovation-driven business enterprises is also one of the more important pathways. Physical capital, such as TTOs and business incubators, can help universities to launch their spin-off companies and create regional innovation impacts such as job creation in local communities. With such assets at their disposal, several universities are well-placed to deliver entrepreneurship support to the business sector, helping to develop more innovative and competitive firms. How universities in Europe go about their entrepreneurship education and how they support enterprise development are the main topics of the next chapter. 